\title{
The Real Epistemic Problem of Cognitive Penetration
}

\section{Harmen Ghijsen}

August 2015

\begin{abstract}
The phenomenon of cognitive penetration has received a lot of attention in recent epistemology, as it seems to make perceptual justification too easy to come by for experientialist theories of justification. Some have tried to respond to this challenge by arguing that cognitive penetration downgrades the epistemic status of perceptual experience, thereby diminishing its justificatory power. I discuss two examples of this strategy, and argue that they fail on several grounds. Most importantly, they fail to realize that cognitive penetration is just an instance of a larger problem for experientialist theories of perceptual justification. The challenge does not lie in explaining how cognitive penetration is able to downgrade the epistemic status of perceptual experience, the challenge lies in explaining why perceptual experience would have a special epistemic status to begin with. To answer this challenge, experientialists have to solve the distinctiveness problem: they have to explain what is so distinctive about perceptual experience that enables it to provide evidential justification without being in need of justification This research was supported by a KU Leuven BOF PDM-K scholarship.

Harmen.Ghijsen@hiw.kuleuven.be
\end{abstract}


itself. Unfortunately, an internalist answer to this problem does not appear to be forthcoming, even though it would certainly help with explaining the problem of cognitive penetration.

Keywords Cognitive penetration $\cdot$ Experientialism $\cdot$ Dogmatism $\cdot$ Distinctiveness problem · Epistemic downgrade

\section{Introduction}

The phenomenon of cognitive penetration has recently received a lot of attention in both philosophy of mind (Macpherson 2012; Wu 2013; Vetter and Newen 2014; Chasid 2014; Zeimbekis and Raftopoulos Forthcoming) and epistemology (Siegel 2012, 2013a; Lyons 2011; McGrath 2013; Tucker 2014; Vahid 2014). The question for philosophy of mind is whether perceptual experience can be truly 'penetrated' by cognition without changing any of the inputs being processed by the perceptual system. That is, the question is whether perceptual experience can be different due to top-down influences that have nothing to do with changing the inputs that are being processed bottom-up. If such cognitive penetration occurs, then perception is not just a receptive process but far more constructive than some have supposed. For the purposes of this paper I will just accept that cognitive penetration of this type is an existing phenomenon. The question that I am here interested in is epistemological in nature: does cognitive penetration present theories of perceptual justification with any new or distinctive problems? My aim is to argue that, despite the attention the phenomenon has so far received in epistemology, cognitive penetration is just an instance of a much larger challenge specific to certain internalist theories of perceptual justification. If internalists feel pressured to amend 
their theory due to the phenomenon of cognitive penetration, I suggest they are better off focusing on this larger challenge, or, better yet, leaving the internalist camp entirely.

In $\S 1$, I briefly present the epistemic problem that arises from the phenomenon of cognitive penetration. Although this problem appears most pressing for dogmatism (Pryor 2000; Huemer 2001), other internalist views also suffer from it. In general, the problem of cognitive penetration seems to target all experientialist theories of perceptual justification, which take perceptual experiences to constitute (defeasible) evidence for beliefs merely on the basis of their being perceptual experiences. ${ }^{1}$ In $\S 2$, I discuss two responses to the problem provided by Susanna Siegel (Siegel 2013a) and Matthew McGrath (McGrath 2013). Both of these responses try to explain how a perceptual experience can be epistemically downgraded by looking at similarities with epistemically pernicious belief-structures. I argue that both these responses leave unexplained why both these experience- and beliefstructures are epistemically pernicious. In $\S 3$, I then present what I take to be the real problem for experientialist views of perceptual justification: instead of explaining how cognitive penetration can downgrade perceptual experience, they have to explain why perceptual experiences would have a special epistemic status to begin with. What is so distinctive about perceptual experience that allows it to provide evidence for belief merely on the basis of it's being a perceptual experience? This problem is even worse for those who, like Siegel and McGrath, take an analogy with belief-structures seriously, as most people agree that beliefs are not able to provide evidence for other beliefs merely on the basis of their nature as

1 Thus, evidentialists like Conee and Feldman (2004) are also in need of a response to this problem. 
beliefs. In $\S 4$, I briefly consider some responses to this broader challenge, and argue that they are unsuccessful. I conclude that experientialists should focus on the challenge raised by the distinctiveness problem rather than focus on an instance of this challenge, i.e., cognitive penetration.

\section{The Problem of Cognitive Penetration}

Let's start discussing the problem of cognitive penetration from the viewpoint of the following theory of perceptual justification:

Perceptual Dogmatism: If it perceptually seems to $\mathrm{S}$ that $\mathrm{P}$, then $\mathrm{S}$ thereby has prima facie perceptual justification for $\mathrm{P}^{2}$

According to this theory of perceptual justification, one can acquire prima facie justification for the belief that $\mathrm{P}$ merely by having a perceptual experience, or perceptual seeming, with a relevantly similar content. ${ }^{3}$ This proposal thus has the benefit of making perceptual justification easily attainable in a way that seems to accord with the phenomenology of how we arrive at our perceptual beliefs. We don't need to reason from premises about our experiences to conclusions about the environment, nor do we need to eliminate skeptical hypotheses; we just need to have a perceptual experience which represents that the world is such-and-so to have justification for the belief that the world actually is such-and-so. Presumably,

2 Proponents of this account of justification include (Pryor 2000; Huemer 2001; Tucker 2010; Chudnoff 2011).

3 See (Ghijsen 2015) for more on the distinction between perceptual experience and perceptual seeming, here I will use the terms interchangeably. 
if one then believes that the world is such-and-so on the basis of this experience, one ends up with a belief that is both propositionally and doxastically justified. ${ }^{4}$

It's important to note that this justification can be defeated by additional considerations. For instance, if one knows that the lighting conditions are strange, then a perceptual experience that the tie in front of you is black might not be sufficient for ultima facie justification of the belief that the tie is black even if it does provide prima facie justification for that belief. We will later see that this provides proponents of perceptual dogmatism with one way of responding to cases of cognitive penetration.

Now, briefly put, the problem that cognitive penetration poses for perceptual dogmatism is that it seems to make justification too easy to obtain. Given that perceptual dogmatism places no requirements on the etiology of a justifying perceptual experience, even experiences that are causally influenced by wildly unjustified beliefs will provide prima facie justification for other beliefs. This seems to be especially distressing because unjustified beliefs are not usually taken as possible starting points for ending up with justified beliefs. Yet perceptual dogmatism has the consequence that as soon as these unjustified beliefs become so powerful that they actually start to cause perceptual experiences which reflect their contents, then they can result in justified beliefs.

\footnotetext{
4 This is important to mention, given that the dogmatist's thesis is usually phrased in terms of propositional rather than doxastic justification. A perceptual experience could provide propositional justification for a subject's belief that $\mathrm{P}$ even if the subject's actual belief that $\mathrm{P}$ is doxastically unjustified because it was not based on the perceptual experience but on some other bad ground (e.g., one's horoscope).
} 
Of course one can complain that this is a slightly misleading way of putting matters, as perceptual dogmatism does not hold that the unjustified beliefs themselves provide prima facie justification for other beliefs. It's just that they might cause certain states (i.e., perceptual experiences) that are capable of providing such prima facie justification. Moreover, there certainly are cases where unjustified beliefs can be the causal starting point for justified beliefs. For instance, my unjustified belief that $\mathrm{X}$ is a bad philosopher might lead me to scrutinize X's arguments, thereby finding a flaw that I would have otherwise overlooked. The unjustified belief causally leads to the belief that the argument is flawed, but this does not detract from the justification of the latter belief.

Still, this last scenario does not appear relevantly similar to that of cases of cognitive penetration. Looking at some examples might strengthen the idea that perceptual dogmatism allows something that is actually epistemically illicit. Take the following case by Peter Markie:

Suppose that we are prospecting for gold. You have learned to identify a gold nugget on sight but I have no such knowledge. As the water washes out of my pan, we both look at a pebble, which is in fact a gold nugget. My desire to discover gold makes it seem to me as if the pebble is gold; your learned identification skills make it seem that way to you.

(Markie 2005, pp. 356-7)

Let's assume for the sake of argument that the perceptual seeming itself, instead of a judgment that results from that seeming, is causally influenced by the desire to discover gold. Then perceptual dogmatism has the result that both sub- 
jects in the example acquire prima facie justification for their beliefs, even though only the expert really has the skills to identify gold.

This is a counter-intuitive result, but one could try to use several strategies to explain away the intuition. For instance, the novice (Markie) but not the expert might have a defeater for his belief as he has no reason to think that he can actually identify gold nuggets on sight. This would mean that even though the perceptual experience of the novice provides him with prima facie justification, he lacks ultima facie justification because of some kind of defeater. However, this line of explanation fails as it is already implausible to take the novice to just have prima facie justification (Tucker 2010, p. 539). Another strategy tries to explain the intuition by appealing to the blameworthiness of the novice in comparison to the expert, or to the fact that the expert but not the novice is in the market for knowledge (Tucker 2010, pp. 539-41). Although these strategies might go some way towards explaining why we think that there is an epistemic difference between the expert and the novice, they still do not seem to explain sufficiently why we (also) have the intuition that the novice is not even prima facie justified considered on his own.

To make this more plausible, consider the following different case by Susanna Siegel:

Jill believes, without justification, that Jack is angry at her. The epistemically appropriate attitude for Jill to take toward the proposition that Jack is angry at her is suspension of belief. But her attitude is epistemically inappropriate. When she sees Jack, her belief makes him look angry to her. 
If she didn't believe this, her experience wouldn't represent him as angry.

(Siegel 2012, p. 209)

In this case, we are not making a comparison between a novice and an expert. Instead, we look at one subject, Jill, who appears to form a belief in a way that is epistemically illicit: her unjustified belief influences her perceptual experience to such a degree that the experience is more of a representation of this prior unjustified belief than a representation of how the world actually is. Now one might again use an appeal to blameworthiness or absence of knowledge to explain away our intuition, but this does not appear very plausible. What's more, externalist accounts are easily able to accommodate the intuition that the subjects are unjustified in these bad cases of cognitive penetration - their belief-forming processes are not reliable, their cognitive systems do not appear to be functioning properly, etc. In the light of this alternative, it seems that cognitive penetration definitely presents a challenge for perceptual dogmatism.

Let me note that the problem for perceptual dogmatism is not just that it allows a seeming manipulated by desire or unjustified belief to produce prima facie justification, as Chris Tucker presents it (Tucker 2014, p. 39). Instead, it necessitates that a manipulated seeming produces prima facie justification, as all perceptual seemings produce prima facie justification independent of their etiology. ${ }^{5}$ But the cognitive penetration problem does not just afflict perceptual dogmatism, it's a challenge for all experientialist theories of perceptual justification that make

\footnotetext{
5 This also means that perceptual dogmatism is, pace (Tucker 2014), worse off than, say, reliabilists accounts of perceptual justification, as these accounts would at worst only allow for prima facie justification in cases of cognitive penetration if the belief-forming process is (conditionally) reliable.
} 
perceptual experiences into evidence for beliefs merely on the basis of their being perceptual experiences. ${ }^{6}$ If merely being a perceptual experience is sufficient to constitute evidence for belief, then all cognitively penetrated perceptual experiences will also constitute evidence for belief, even if the cognitive penetrator is epistemically outrageous. The problem seems to be that, just as unjustified beliefs cannot constitute evidence for beliefs, badly cognitively penetrated experiences also cannot constitute evidence for beliefs. This points to the fact that the etiology of an experience should be taken into account when considering that experience's epistemic status. The next section will consider two internalist proposals which attempt to do just that.

\section{Accommodating Etiology Internalistically}

In the previous section we saw that bad cases of cognitive penetration present a challenge to experientialist theories of perceptual justification that do not take an experience's etiology into account in determining its justificatory power. Before going to Siegel's (2013a) and McGrath's (2013) responses to this problem, let me remark that there are also some internalists that are not worried about cognitive penetration. These hard-liners just accept that cognitively penetrated experiences produce prima facie justification as long as the cases are set up in a way that no defeaters are present (Fumerton 2013; Huemer 2013). An important motivation for this view is that it seems irrational not to accept one's perceptual experiences in the absence of any reasons to distrust them. If one has a cognitively penetrated perceptual experience in the absence of any defeaters, then the only rational thing

\footnotetext{
6 This point is also made in different terms by (Siegel 2012, p. 219-21).
} 
to do is to believe what the experience is telling you. Although I agree that there would be something irrational about a subject who mistrusted his experiences without reason, this property of irrationality simply does not track the property of epistemic justification. McGrath (2013) argues this point by using the following example:

Suppose my evidence strongly points against $\mathrm{P}$ and against $\mathrm{Q}$, but that nevertheless I believe P. Then, if I continue to believe P, coherence requires that I believe the disjunctive proposition $P$ or $Q$ if I entertain the question [...] We want to say that it is reasonable for me to believe $P$ or $Q$, insofar as I already have a belief that $\mathrm{P}$.

(McGrath 2013, p. 229)

Even though it certainly is reasonable, in some sense of the term, for me to believe $P$ or $Q$ given that I already believe that $\mathrm{P}$, in this case the belief is still definitely not epistemically justified, given that I also have strong evidence against P. Perhaps the positive epistemic property of the belief that $P$ or $Q$ can be called conditional justification, given that it would be justified on the condition that $\mathrm{P}$ is justified. ${ }^{7}$ Whatever one likes to call it, it is not the same as the property of epistemic justification that we have so far been concerned with.

\subsection{Downgraded Experiences}

Susanna Siegel $(2012 ; 2013 a)$ does see the need for an alternative account, compatible with internalism, that can accommodate the cognitive penetration prob-

\footnotetext{
7 See (Lyons 2013) for more on the notion of conditional justification, and the role this
} notion could also play in accounting for the New Evil Demon case. 
lem. According to Siegel, experiences can have rationally assessable etiologies that might downgrade their epistemic status in a way that is different from their merely being (conditionally) unreliable. Such rationally assessable etiologies are to be distinguished from etiologies that are a-rational because they have no connection to any rational cognitive processing whatsoever. The idea is that the formation of some beliefs or experiences could be "zaplike" (Siegel 2013a, p. 700) in the sense that they are caused by e.g., God, or, less extreme, a bump on the head; causes that have nothing to do with arriving at experience- or belief-outputs on the basis of the kind of cognitive processing we would ordinarily take as rational.

Once we accept this distinction between rationally assessable and a-rational etiologies, Siegel claims we can define a certain type of epistemically downgraded experience in the following way:

An experience $\mathrm{E}$ with content $\mathrm{C}$ and etiology $\mathrm{X}$ is checkered with respect to C iff:

- $\mathrm{X}$ is rationally assessable, and

- a belief with content $\mathrm{C}$ and etiology $\mathrm{X}^{*}$ would be doxastically unjustified, where the output of $\mathrm{X}^{*}$ is a belief with no intervening experience, and $\mathrm{X}^{*}$ has psychological elements sufficiently similar to X's.

(Siegel 2013a, p. 716, my italics)

Thus, the thought behind Siegel's account is that some experiences, i.e., checkered experiences, lack the power to (fully) justify certain beliefs because their etiology is sufficiently similar to an etiology that would have led to unjustified belief. So we no longer need to accept that in intuitively bad cases of cognitive penetration, the perceptual experiences still provide immediate justification for 
the relevant beliefs. Their epistemically bad etiologies lead to an epistemic downgrade that prevents them from providing sufficient justification for the relevant beliefs.

Although there seems to be something right about the idea of epistemic downgrade, we've been given rather crude tools to determine whether experiences are checkered and thus downgraded. A reasonable question to ask is precisely when experience-etiology $\mathrm{X}$ is sufficiently similar to the bad belief-etiology $\mathrm{X}^{*}$. Take the case of Jill and Jack again. One might claim that the etiology X of Jill's cognitively penetrated experience that Jack looks angry (recall: it's due to her prior unjustified belief that Jack is angry) is comparable to an etiology $\mathrm{X}^{*}$ where Jill re-assesses her belief that Jack is angry and on the basis of that belief alone again concludes that Jack is angry. The belief that results from $\mathrm{X}^{*}$ certainly looks unjustified, and this would thus make etiology $\mathrm{X}$ result in a checkered experience. But, as Hamid Vahid (2014) points out, what about a similar case with etiology Y in which Jill actually becomes more sensitive to Jack's emotional state (which happens to be one of anger) because of her unjustified belief that Jack is angry? ${ }^{8}$

According to Siegel, etiology $\mathrm{Y}$ is relevantly different from etiology $\mathrm{X}^{*}$, and should rather be compared to etiology $\mathrm{Y}^{*}$ in which Jill's theory of mind improves and on the basis of which Jill then figures out that Jack is angry (Siegel 2013a, p. 716). For instance, if Jill thinks about the reasons for Jack's anger because of her unjustified belief that he is angry, and then truly realizes that Jack must be angry because he had eggs for breakfast even though he hates eggs, then the belief that Jack is angry could turn out to be justified after all. The idea seems to be

\footnotetext{
8 Such cases of good cognitive penetration have also been raised as problems for Siegel's
} account by Jack Lyons (2011). 
that being more sensitive to Jack's emotional state in etiology Y should be taken as an intermediary step that should also show up in the compared belief-etiology $\mathrm{Y}^{*}$.

However, it is difficult to see how we could, on this basis, end up with a principled way of determining similarity of etiologies. Siegel herself claims that even those cases in which cognitive penetration occurs via an effect on attention (e.g., Jill focuses more on specific anger-correlated facial features of Jack) can be cases of checkered experiences (Siegel 2013a, p. 717). ${ }^{9}$ But it is difficult to see why such a case wouldn't be similar to the one in which Jill's theory of mind improves. Siegel appears to rely on prior intuitions about the epistemic (im)propriety of cognitive penetration in her determination of the sufficiently similar belief-etiologies, but that is exactly the opposite of how the account was supposed to work. The account was supposed to tell us when a case of cognitive penetration was bad on the basis of a similar belief-etiology, rather than tell us which belief-etiology was similar on the basis of whether a case of cognitive penetration was bad. To have a good theory of checkered experiences, we first need a good account of similarity between etiologies, and from there we can then determine whether all our intuitions about cognitive penetration are accommodated. As it stands, the suggestion appears too imprecise to be fully satisfying.

Next to this complaint about determining etiology-similarity, a different complaint could be raised about the explanatory power of Siegel's suggestion. Suppose that we were able to provide a precise way of determining the sufficient similarity between experience- and belief-etiology that Siegel's account appeals to. There would then still be a question as to why beliefs and experiences with those etiolo-

\footnotetext{
9 Note that the example in parentheses is not one that Siegel herself provides.
} 
gies are unable to confer justification onto further beliefs. What is it about being this specific kind of etiology that makes the resulting experiences and beliefs into downgraded epistemic states? It should be clear that one answer, that these etiologies are simply (conditionally) unreliable, is off the table, as Siegel wants to uphold an account compatible with a variety of internalist rather than externalist positions.

Instead, Siegel proposes that we should look at this question in a rather different light. According to Siegel, perceptual experiences share a certain property with beliefs that make them into possible "conduits of ill-foundedness" (Siegel 2013b, p. 754): they are both ways of endorsing certain contents. Contrast this with, say, suppositions, mental states which also have propositional contents, but, unlike perceptual experiences and beliefs, do not endorse those contents in any way. Now, the fact that both perceptual experience and belief are endorsements of contents could be used to explain why they can be epistemically downgraded when they have certain etiologies. When an unjustified content is part of the etiology of an experience or a belief, and this content is then endorsed by the experience or the belief, the experience or belief have thereby become conduits of ill-foundedness: they are no longer able to confer justification onto further beliefs which result from the wrongly endorsed content.

This suggestion seems fine when one considers cases in which one starts from an unjustified belief and then goes on to experience or further belief. However, the phrase "conduit of ill-foundedness" already hints at a problem: to be a conduit of ill-foundedness, ill-foundedness has to be already there to be transmitted. The problem becomes more clear once one looks at cases in which desires or fears figure in the relevant etiologies. These mental states might not be capable of having 
unjustified contents in the way that beliefs can, in which case there would be no ill-foundedness to transmit. But even if they were capable of having such contents, then it still is not true that an endorsement of such contents is always epistemically improper. Examples of such cases are again those in which the desires or fears actually make one more sensitive to the environment. In such cases, the resulting perceptual experience is not downgraded at all, even though it could still be an endorsement of the earlier content of desire or fear. ${ }^{10}$

So Siegel does have a problem in explaining what it is about belief- and experience-etiologies that can downgrade their epistemic status. Nevertheless, we certainly have some clear intuitions about which etiologies are epistemically good, and which are epistemically bad. But this could easily be explained by pointing to the fact that certain etiologies make experiences less sensitive to how the world actually is, an explanation that is unfortunately of no help to someone who wants to accommodate the problem of cognitive penetration in a way compatible with $i n$ ternalism about perceptual justification. Internalists are thus in need of a different answer to the problem of cognitive penetration.

\footnotetext{
10 Siegel could retort that these latter cases are ones in which the content is not endorsed only because of the ill-founded states in the etiology. But this seems to be true for almost any plausible case of cognitive penetration; surely the environment always has some impact on the experience. The question is exactly when the impact of the environment becomes too small, and the intuitive answer to this question would appeal to a subject's remaining sensitive enough to changes in the environment - again, though, this answer is not open to internalists.
} 
2.2 Receptive Seemings

Just as Siegel, McGrath (2013) recognizes that cognitive penetration forms a challenge for the usual internalist theories of perceptual justification. And, like Siegel, McGrath also thinks that some experiences can be epistemically downgraded to such an extent that they are no longer able to provide immediate justification. Only those experiences, or as McGrath prefers, seemings, that are receptive or properly quasi-inferred from receptive seemings can justify a subject in believing their contents. Let's start by looking at the notion of a quasi-inference, with which we can then distinguish between receptive and nonreceptive seemings:

Let us say that a transition from a seeming that $\mathrm{P}$ to a seeming that Q is "quasi-inferential" just in case the transition that would result from replacing these seemings with corresponding beliefs that $\mathrm{P}$ and $\mathrm{Q}$ would count as genuine inference by the person [... I I claim that quasi-inferential transitions between seemings function epistemically in the way inference by the person does: they can at best transmit the relevant epistemic property of the inputs to the outputs; they cannot generate this property for the outputs when it isn't possessed by the inputs. In the case of inferential transitions between beliefs, the epistemically relevant property which can be transmitted is doxastic justification. In the case of transitions between seemings, the property is justifying the subject in believing its content.

(McGrath 2013, p. 237)

With this notion of quasi-inference in hand, one can now distinguish between receptive and nonreceptive seemings, where receptive seemings are ones that are not outputs of quasi-inferential transitions and nonreceptive seemings are outputs 
of such transitions. According to McGrath, only receptive seemings generate the property of justifying their subjects in believing their contents; nonreceptive seemings just receive this property by transmission from receptive seemings by means of a good quasi-inferential transition.

To find out which quasi-inferences are good, and which are bad, we first have to know more about the conditions for there being any kind of inference in the first place. According to McGrath, at least the following conditions are necessary:

(i) the input and output states [...] must be mental states of the person, not merely of a sub-personal system; and (ii) there must be an explanation in terms of the person's own mental states that "rationalizes" the transition, i.e., that allows us to see the transition as the person's treating the content of the input state as supporting the content of the output state.

(McGrath 2013, p. 238)

Condition (ii) is relevant in determining whether a quasi-inference is good. If a subject just jumps from the seeming that something looks yellow to the seeming that it must be gold on the basis of his desire for gold, then there is an explanation in terms of the person's own mental states that "rationalizes" the transition: because of his desire for gold, the person treats the content of the input state as supporting the content of the output state. However, McGrath agrees that a quasiinferential transition of this sort certainly isn't a good one. Good quasi-inferences, in contrast, are those in which the rationalizing mental states are constituted by a subject's background knowledge. In combination with such background knowledge, lower-level seemings of yellowish shapes will sufficiently support higher-level seemings of gold. 
This already shows how the account is supposed to play out in problematic cases of cognitive penetration. In bad cases of cognitive penetration, receptive seemings have been "freely enriched" (McGrath 2013, p. 237) by wishful thinking or unjustified beliefs to deliver nonreceptive seemings that are no longer able to justify their subjects in believing their contents. The problem is that the nonreceptive seemings (e.g., as of gold) are not adequately supported by the receptive seemings (as of a yellow pebble) in the absence of any background knowledge, and therefore not quasi-inferred in a proper way.

Unfortunately, this response to cognitive penetration is severely problematic for several reasons. First, as I argue elsewhere (Ghijsen 2015), there's simply no strong empirical support for the claim that there are inferential transitions between two personal-level states in ordinary cases of perception. Although our best theories of perception might claim that there are several subpersonal states which represent different aspects of external stimuli (e.g., first features like contrast and luminance are represented, then features are integrated to represent objects, etc.), there's no reason to assume that these separate subpersonal states are also reflected as separate states at the personal level. If this is true, then quasi-inference as it is described by McGrath simply does not occur, thereby eliminating the possibility of explaining problematic cases of cognitive penetration as cases of epistemically faulty nonreceptive seemings. ${ }^{11}$

\footnotetext{
11 Although one might try to solve this problem by allowing for quasi-inferences between subpersonal states, this only leads to other difficulties. Subpersonal mechanisms are always "jumping to conclusions" on the basis of cues that underdetermine the actual facts, in which case no seemings would count as receptive.
} 
Second, even if we assume that quasi-inferences are psychologically real, then there is still a worry about the explanatory power of McGrath's suggestion. McGrath, like Siegel, uses a comparison with belief to make sense of the notion of good quasi-inferences. This comes out clearly when McGrath discusses the seemingtransition for an expert bird watcher to whom it perceptually seems that a certain bird is a pine warbler:

Suppose there is a seeming-transition here: the bird seems to be a pine warbler as a result of its seeming to have certain other features which it is hard to articulate, its seeming to have a pine warbler gestalt. Is this a quasi-inferential transition? If it is explained by appeal to the person's knowledge of the observable features of pine warblers, then the answer is yes. Suppose someone, by virtue of this knowledge, based a belief that the bird is a pine warbler on the belief that the bird had such and such gestalt. This would count as inference, I think. When these beliefs are exchanged for seemings, the result is a quasi-inferential seemings-transition and so a nonreceptive output seeming.

(McGrath 2013, p. 241)

What, in this case, makes the seeming-transition from the bird's seeming to have a pine warbler gestalt to the bird's seeming to be a pine warbler a good quasi-inference? The fact that, if the seemings had been beliefs, there would have been an intuitively proper inference, given the expert's background knowledge. The background knowledge is essential for McGrath's proposal, as this is the crucial element that distinguishes the expert birdwatcher from a novice to whom it inappropriately (due to wishful thinking) seems that the bird is a pine warbler. But 
the problem precisely lies in spelling out the nature of this background knowledge. If this is theoretical knowledge of the form that pine warblers look like this, then it's unclear where this knowledge finds its origin. It cannot be based on receptive seemings, as identifying pine warblers on the basis of receptive seemings presupposes that one already has this background knowledge - after all, this requires a good quasi-inference leading from the pine-warbler-gestalt-seeming to the being-a-pine-warbler-seeming.

Induction and testimony will not help for similar reasons. For induction, one needs to justifiably believe that there was a pine warbler when I had this lower-level seeming at $t_{1}$, that there was a pine warbler when I had this lower-level seeming at $t_{2}$, etc., and one simply cannot justifiably believe that there was a pine warbler at those times without already having had the right kind of higher-level receptive seemings at those times. For testimony, one would first have to explain how one could have properly receptive higher-level seemings of someone's saying that pine warblers look such-and-so on the basis of lower-level seemings of sounds. And this just asks for further background knowledge (about the relation between sounds and spoken words) that would then stand in further need of being explained.

It thus seems better to think of the background knowledge in question as know-how, an identification with which McGrath also seems to agree (2013, p. 238; p. 242). But this raises a question as to what know-how comes down to exactly. An externalist reading would identify this know-how with a person's ability to reliably identify pine warblers when one encounters them, something that should not be included in McGrath's internalist response to the problem of cognitive penetration. So McGrath must have something else in mind when he speaks of a subject's knowhow as explaining what grounds epistemically good quasi-inferences. The notion 
he has in mind is elucidated when he compares know-how to mental states that could masquerade as it:

What if the pine-warbler-seeming is the output of a quasi-inferential transition, but the transition is made not because of the person's learned identificatory skills but because of a mental state masquerading as learned identificatory "know-how"? [...] Imposters might include unreliable dispositions resulting from poor training (e.g., the disposition to see something as a cardinal bird if one sees it as yellow and small) and reliable but unlearned dispositions (e.g., those which result, say, from "last night's neurosurgery" as Jack Lyons (2011) imagines). In either case, these are not "know-how" but at best "belief how," if you will. Whether the resulting seeming justifies will therefore depend on whether such "belief how" makes it the case that the content of the input seeming sufficiently supports the content of the output seeming for the subject. It presumably does not if the "belief how" counts as unreasonable but may if it counts as reasonable.

(McGrath 2013, p. 242, n. 32)

According to McGrath, know-how is neither a learned unreliable disposition, nor a reliable unlearned disposition. Instead, know-how appears to be constituted by learned reliable dispositions. But the reliability of a learned recognitional disposition is not something that is accessible to the subject, nor is it part of the subject's mental states. The same disposition to go from lower-level seemings to higher-level seemings need not be reliable in different environments. For instance, there might be environments in which cardinal birds (and cardinal birds only) really have evolved to be yellow and small, in which case the disposition to see 
something as a cardinal bird if one sees it as yellow and small is reliable after all in that environment. This means that there is nothing intrinsic about the relation between lower-level seemings and higher-level seemings that makes having the tendency to go from the one to the other into a reliable recognitional disposition. The reliability of this recognitional disposition should therefore not be taken to be part of the subject's mental states, and therefore not as a factor to which internalists about justification can appeal.

So McGrath does appear to rely on externalist factors in grounding epistemically good quasi-inferential transitions. However, one might claim that it is not really the reliability of the disposition that grounds good quasi-inferences. Instead, what grounds the good quasi-inference is the fact that there just is a learned disposition to go from a lower-level seeming to a higher-level seeming rather than a sudden "jump" from the one to the other on the basis of an unjustified belief or desire. This accords with the fact that McGrath is open to the idea that reasonable "belief-how" can also ground good quasi-inferences. Unfortunately, without reliability in the picture, we just end up with the problem we started out with: perceptual justification will become too easy to obtain. Suppose I trust the testimony of someone who is no expert in ornithology at all. ${ }^{12}$ This can be entirely reasonable if the person confidently and at least seemingly consistently asserts which type of birds we are looking at. On the basis of his testimony, I come to have several learned dispositions to go from lower-level seemings about shapes and colors to higher-level seemings about kinds of birds. Unfortunately, because the person I trusted was no expert at all, I come to have wrong seemings about birds

12 Let's bracket the earlier mentioned issue of coming to have higher-level seemings about what someone is saying on the basis of lower-level seemings about sounds. 
all the time. In this case, the higher-level bird-seemings just do not appear to justify me in believing their contents. And another type of example is easily found: I might reasonably think I'm picking up on distinctive features of birds (say, their color), thereby acquiring a disposition to go from certain lower-level seemings to higher-level seemings (if it's brown, then it's a sparrow) but I might not be tracking any distinctive features at all. Again, the higher-level seemings I would then have would not appear to justify me in believing their contents. The moral of the story seems to be that higher-level seemings will not provide any justification if the dispositions they are based on are not reliable.

Briefly summarized, the problem appears to be the following. McGrath, like Siegel, attempts to discriminate good and bad seeming-transitions by comparing them to what would be good and bad belief-transitions. But the proposed good type of belief-transition appeals to a certain factor, i.e., background knowledge, that cannot be appealed to in the case of seeming-transitions. Higher-level seemings are needed in the first place to explain how we could arrive at propositional background knowledge, and know-how only gets one to the correct result if it also incorporates a reliability constraint, a factor to which internalists cannot appeal. What's more, once one uses reliability to distinguish between good and bad quasi-inferences, there really is no more need for a comparison between belief- and seeming-transitions anyway. One can simply explain what is good about certain seeming-transitions immediately in terms of reliability. In good cases of cognitive penetration, the process from experience to belief is reliable, while this is not true for bad cases of cognitive penetration. However, this is exactly not the type of explanation an internalist would want to appeal to in accommodating the problem of cognitive penetration. 
McGrath's proposal thus lacks a good internalist explanation of what makes seeming-transitions epistemically (in)appropriate. But even if one could point to an internalist factor to explain why a certain transition from a lower-level seeming to a higher-level seeming is inappropriate, then there is an important problem left. McGrath's solution simply does not get at the heart of the cognitive penetration problem by focusing only on the transition from lower-level (receptive) seemings to higher-level (nonreceptive) seemings because, as McGrath himself mentions (2013, p. 239, n. 25), empirical research suggests that cognitive penetration can occur even at the earliest level of visual processing (Hansen et al 2006). If this is the case, then one would expect that there can also be epistemically bad cases of cognitive penetration at the lowest level, i.e., the level of receptive seemings. McGrath's account will have no solution for such cases of cognitively penetrated yet receptive seemings, and will have to say that they are able to provide immediate justification. ${ }^{13}$ If one is satisfied with such an account of low-level cognitive penetration - perhaps because one believes that the relevant intuitions can be explained by appeal to defeat, blameworthiness, etc. - then one might as well be satisfied with such an account at a higher level.

So neither McGrath nor Siegel are able to accommodate the problem of cognitive penetration. The moral of the critique is that one cannot provide a good internalist account of cognitive penetration in terms of the similarity between good and bad experience-etiologies and good and bad belief-etiologies if one lacks an adequate internalist account of what makes those etiologies good or bad in the first place. But to find such an adequate account, internalists will first have to provide

13 The same worry about not accommodating low-level cognitive penetration also applies to Elijah Chudnoff's (2013) solution to the problem. 
an answer to a challenge that is even worse, namely that of the distinctiveness problem. The next section will turn to this problem.

\section{The Real Epistemic Problem of Cognitive Penetration}

Briefly put, we've seen that the problem of cognitive penetration is that there are cognitively penetrated perceptual experiences that are intuitively unable to provide sufficient justification for belief because of their bad etiologies. Overly strong desires, unjustified beliefs, fears, all these states might influence experience to such a degree that the experience becomes more of a representation of the content of these prior states than of what they are supposed to represent, i.e., the subject's environment. However, so far we have not been given any reason to think that this focus on cognitively penetrating states is not just a red herring.

What about the following case? You bump your head and start to hallucinate. According to Siegel (2013a), such an experience would have an a-rational etiology, and on that basis not be a candidate for epistemic downgrade, or at least not for the same reasons as experiences with a checkered past. ${ }^{14}$ But we could also just group experiences with checkered pasts together with experiences that have a-rational etiologies as types of experiences that are both part of unreliable belief-forming processes. ${ }^{15}$ On this line of thought, cognitive penetration is just one intuitive illustration of the fact that perceptual experiences do not provide any justification just because they are perceptual experiences. The problem for internalists would then be much bigger than showing how and when perceptual experiences can be

\footnotetext{
14 This last remark is needed because Siegel wants to leave open whether experiences with arational etiologies can be epistemically downgraded for different reasons (Siegel 2013a, p. 700). 15 This is the line taken by Jack Lyons (2011).
} 
epistemically downgraded, the problem would then consist in showing why we should think that anything would be able to provide justification just in virtue of being a perceptual experience to begin with.

So what internalists need is a good reason to keep experiences with a checkered past apart from experiences with a-rational etiologies. Siegel tries to motivate the distinction by another comparison to belief: in some cases of forming beliefs "we would not regard either ourselves or any of our subpersonal systems as convicted of any error if we ended up with those beliefs via that kind of process, nor would we regard the processes as making the belief rational" (Siegel 2013a, p. 713). The relevant cases are ones in which beliefs are "zapped" into you by some external cause; this process is not one that makes the belief rational, nor is it a process to which one can ascribe a certain error. Siegel's thought seems to be that when experiences or beliefs arise because of prior cognitive processing, then the rationality of these experiences or beliefs can be explained by looking at the contents of the prior states that led to them. In the absence of prior cognitive states, beliefs and experiences simply stop being rationally assessable, as there are no prior states on the basis of which these beliefs and experiences could be assessed.

However, this line of thought is mistaken in two respects. First, by just looking at the contents of prior mental states, one will not be able to assess whether a certain resulting state is rational or not. It might be rational to go from content A to content $\mathrm{B}$ in a certain environment, but not so in a different environment. The color of a certain bird might be sufficient to rationally conclude its kind in one environment (where only this kind of bird has that particular color), but not in another (where other kinds of birds have the same color). Second, even without prior mental states, there might still be ways to rationally assess experience or 
belief. For instance, one could say that bumping one's head is a bad way of arriving at a perceptual experience of an apple, as this is not a reliable way to come to have accurate representations of apples. The perceptual experience might thus be called irrational in response to the bumping of one's head.

The point is that we have not been given any reason to think that rationality is necessarily connected to evidential transitions between contents. Without such a reason, the different treatment of checkered experiences and zaplike experiences is entirely optional. And now the question is whether we should still hold on to the idea that these experiences should be treated separately, that is, hold on to the idea that there is something specifically problematic about cognitive penetration, or, accept that there is a general problem about the justificatory force of experience of which cognitive penetration is just one illustration.

Interestingly, there is reason to prefer the latter answer (Lyons 2009; Ghijsen 2014). The way in which perceptual experiences are supposed to provide justification for beliefs is similar to the way in which beliefs provide justification for other beliefs: they act as evidence on the basis of which a certain content is justified. In other words, perceptual experiences, like beliefs, are supposed to evidentially justify other beliefs. But most people agree that beliefs need to fulfill some conditions other than their being beliefs to provide this justification. In particular, beliefs need to be justified themselves before they can evidentially justify any other belief. This need not lead to a regress of justification, as one can allow that some beliefs are non-evidentially justified by, e.g., being the output of a reliable process. ${ }^{16}$ Now, if one takes the analogy between perceptual experience and belief

\footnotetext{
16 See (Lyons 2009) for more on the distinction between evidential and non-evidential justification.
} 
seriously, as Siegel and McGrath certainly do, then one would expect there to be a similar condition on perceptual experience: only those perceptual experiences that are justified themselves are capable of evidentially justifying beliefs. In the absence of a reason why perceptual experiences are not like beliefs in this respect, there simply is no reason to assume that perceptual experiences have the special epistemic status that Siegel and McGrath take them to have.

This challenge is strengthened by reflection on the fact that there are also paradigm states incapable of evidentially justifying beliefs. For instance, a desire that $\mathrm{P}$ or an imagination that $\mathrm{P}$ cannot evidentially justify a belief that $\mathrm{P}$. Both this fact, and the fact that beliefs need to be justified before they can evidentially justify other beliefs, can be explained by supposing that all evidential justification arises from states that are justified themselves. This leads to a problem, introduced by Jack Lyons (2009), that I have called the distinctiveness problem (Ghijsen 2014): if one wants to uphold the idea that perceptual experiences have some sort of special epistemic status, then one has to explain what is so distinctive about them that allows them to evidentially justify beliefs (in contrast with desire and imagination) without having to be justified themselves (in contrast with belief).

Note that this problem does not just arise for perceptual dogmatism. It is a problem for all experientialist theories of perceptual justification, which suppose that perceptual experiences provide evidence for belief simply on the basis of their being perceptual experiences. What one needs to explain is why perceptual experience is such that no other conditions for providing evidence are required, given that these other conditions are important in other paradigm cases of evidential justification. 
Now I don't think that one can find a satisfying response to this problem without at least committing to some form of externalism. For instance, if one holds that experiences can be justified (or epistemically proper) if they are reliable representations of the environment, or if they are functioning properly, then one has an explanation of when experiences can evidentially justify beliefs in the way that other beliefs can. One could also just reject the entire idea of evidentially justifying experiences, and instead commit to the idea that perceptual justification is simply non-evidential in nature (Lyons 2009). Perceptual experiences are then merely taken as part of a cognitive process that delivers justified beliefs because of the reliability of the entire process. Of course, this is of no avail to Siegel and McGrath, who want to have an account of the epistemic status of experience that is compatible with internalism.

Nevertheless, if internalists are able to come up with an answer to the distinctiveness problem, then that also provides an important first step in answering the cognitive penetration problem from an internalist perspective. An answer to the distinctiveness problem will supposedly provide a property of perceptual experience that explains why it is able to evidentially justify belief without being justified itself, a property that explains its special epistemic status. Bad cases of cognitive penetration could then be expected to be cases in which this property of perceptual experience is somehow negatively affected. All the more reason for internalists to leave the problem of cognitive penetration for later, and focus on the distinctiveness problem first.

Now one might think that internalists actually have some good suggestions at their disposal for answering the distinctiveness problem, and, with it, the problem 
of cognitive penetration. Before going to the conclusion, I will briefly discuss some of these suggestions in the next section.

\section{Responses to the Distinctiveness Problem}

A first internalist response to the distinctiveness problem might focus, along the lines of Siegel (2013b, pp.754-5), on the nature of beliefs and perceptual experiences as endorsements of contents. ${ }^{17,18}$ On this response, beliefs and experiences are able to provide evidence, unlike, say, desires, imaginations and suppositions, because they are endorsements of contents. However, not just any endorsement can evidentially justify beliefs; what's needed is that the endorsements are arrived at rationally. For beliefs, this means that they need to be held for good reasons, whereas for experiences, it means at least that they should not be the result of cognitive penetration by wishful thinking or overly strong desires.

For this suggestion to work, we do need a further account of when experiences are arrived at rationally, given that it's problematic to appeal to similarities with belief-etiologies. But any attempt at providing such an account seems to run into the problem of an infinite regress: prior cognitive states that are supposed to rationalize experiences will need to have some good rational standing themselves, and this will presuppose further states with good rational standings, and so on. This is exactly why an externalist account that allows for non-evidential justification

17 This suggestion and some of its problems were provided by an anonymous referee.

18 Note also that, as Siegel (2013b, p. 756) recognizes, an appeal to phenomenology is unlikely to help, given that badly cognitively penetrated experiences have the same phenomenology as good perceptual experiences. See (Ghijsen 2014) for more worries about a phenomenalist answer to the distinctiveness problem. 
is so appealing: one can end the regress by accepting the possibility of states that are justified without depending on rationalizing prior states.

And there is another difficulty for the suggestion that evidential justification can only be provided by endorsements that are rationally arrived at. Many internalists, including Siegel (2013a, pp.699-700), want to allow that hallucinations and other experiences with a-rational etiologies can also justify one's beliefs. But endorsements with a-rational etiologies, like hallucinations, are ipso facto not endorsements that are arrived at rationally. So the suggestion simply does not work even by the experientialist's own lights.

Perhaps the suggestion can be made to work if it is weakened to the thesis that evidential justification can be provided only by endorsements that are not irrationally arrived at. Again we would still need a better account of what counts as an irrational etiology for experience, but at least it might evade the principled problem of infinite regress by allowing for a-rationally arrived at justifying states (including hallucinations) — which are different from irrationally arrived at states. Promising as this suggestion might look for experiences, it is simply a non-starter for beliefs. A-rationally arrived at beliefs of the zapped kind cannot evidentially justify other beliefs, so there would still be an unexplained difference between experience and belief.

A final response to the distinctiveness problem might therefore simply take the special epistemic status of perceptual experience as primitive, something that Siegel has also suggested (2013b, p. 757). But this answer to the distinctiveness problem places experientialists in a dialectically weak position, as several forms of externalism are able to provide a more developed answer to the question of when and why perceptual experiences are able to provide (evidential) justification for 
belief. What's more, taking the special epistemic status of perceptual experience as primitive also leaves experientialism without a satisfying reply to the problem of cognitive penetration. All in all, then, experientialists would do well to seriously consider the distinctiveness problem before turning to the problem of cognitive penetration.

\section{Conclusion}

I have argued that bad cases of cognitive penetration are just one illustration of a much larger problem for experientialist theories of perceptual justification: they have to explain what is so distinctive about perceptual experience that enables it to provide evidence for beliefs merely on the basis of its being a perceptual experience, given that beliefs are unable to provide such evidence merely because they are beliefs. This problem is especially pressing for philosophers who, like Siegel and McGrath, attempt to answer the problem of cognitive penetration by appealing to an analogy with belief. Even if one were able to find a way to match bad experience-etiologies to bad belief-etiologies, one still has to explain what it is about such etiologies that makes them epistemically illicit. Unfortunately, there is good reason to think that the best explanation of this fact will be externalist rather than internalist in nature.

Acknowledgements Thanks to all members of the Leuven Epistemology Group (LEG), and especially to Chris Kelp and Mona Simion for their helpful comments and suggestions. Also thanks to an anonymous referee for some valuable suggestions to improve the paper. 


\section{References}

Ghijsen, H. (2014) Phenomenalist dogmatist experientialism and the distinctiveness problem 191(7):1549-1566.

Ghijsen, H. (2015) Grounding Perceptual Dogmatism: What are Perceptual Seemings? $53(2): 196215$.

Chasid A (2014) Visual experience: Cognitive penetrability and indeterminacy. Acta Analytica 29(1):119-130

Chudnoff E (2011) The nature of intuitive justification. Philosophical Studies 153:313-33

Chudnoff E (2013) Intuition. New York: Oxford University Press.

Conee E, Feldman R (2004) Evidentialism: Essays in Epistemology. New York: Clarendon Press

Fumerton R (2013) Siegel on the epistemic impact of "checkered" experience. Philosophical studies 162(3):733-739

Graham PJ (2012) Epistemic entitlement. Noûs 46(3):449-482

Hansen T, Olkkonen M, Walter S, Gegenfurtner KR (2006) Memory modulates color appearance. Nature neuroscience 9(11):1367-1368

Huemer M (2001) Skepticism and the Veil of Perception. Lanham, MD: Rowman \& Littlefield Publishers

Huemer M (2013) Epistemological asymmetries between belief and experience. Philosophical studies $162(3): 741-748$

Lyons J (2009) Perception and Basic Beliefs: Zombies, modules and the problem of the external world. USA: Oxford University Press

Lyons J (2011) Circularity, reliability, and the cognitive penetrability of perception. Philosophical Issues 21(1):289-311

Lyons JC (2013) Should reliabilists be worried about demon worlds? Philosophy and Phenomenological Research 86(1):1-40

Macpherson F (2012) Cognitive penetration of colour experience: Rethinking the issue in light of an indirect mechanism. Philosophy and Phenomenological Research 84(1):24-62

Markie P (2005) The mystery of direct perceptual justification. Philosophical Studies 126(3):347-373 
McGrath M (2013) Phenomenal conservatism and cognitive penetration: The "bad basis" counterexamples. In: Tucker C (ed) Seemings and Justification, New York: Oxford University Press, pp 225-247

Pryor J (2000) The skeptic and the dogmatist. Noûs 34(4):517-549

Siegel S (2012) Cognitive penetrability and perceptual justification. Noûs 46(2):201-222

Siegel S (2013a) The epistemic impact of the etiology of experience. Philosophical Studies 162(3):697-722

Siegel S (2013b) Reply to fumerton, huemer, and mcgrath. Philosophical Studies 162(3):749757

Tucker C (2010) Why open-minded people should endorse dogmatism. Philosophical Perspectives 24(1):529-545

Tucker C (2014) If dogmatists have a problem with cognitive penetration, you do too. Dialectica $68(1): 35-62$

Vahid H (2014) Cognitive penetration, the downgrade principle, and extended cognition. Philosophical Issues 24(1):439-459

Vetter P, Newen A (2014) Varieties of cognitive penetration in visual perception. Consciousness and cognition $27: 62-75$

Wu W (2013) Visual spatial constancy and modularity: Does intention penetrate vision? Philosophical studies 165(2):647-669

Zeimbekis J, Raftopoulos A (eds) (Forthcoming) The Cognitive Penetrability of Perception. Oxford: Oxford University Press 